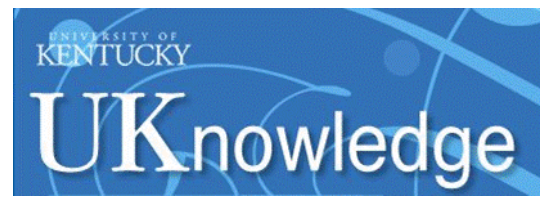

University of Kentucky

UKnowledge

Pharmacy Practice and Science Faculty

Publications

Pharmacy Practice and Science

9-4-2017

\title{
Vena Cava Filter Retrieval Rates and Factors Associated with Retrieval in a Large US Cohort
}

\author{
Joshua D. Brown \\ University of Florida, joshua.brown@ufl.edu \\ Driss Raissi \\ University of Kentucky, driss.raissi@uky.edu \\ Qiong Han \\ University of Kentucky, qiong.han@uky.edu \\ Val R. Adams \\ University of Kentucky, val.adams@uky.edu \\ Jeffery Talbert \\ University of Kentucky, jeff.talbert@uky.edu
}

Follow this and additional works at: https://uknowledge.uky.edu/pps_facpub

Part of the Cardiovascular Diseases Commons, and the Pharmacy and Pharmaceutical Sciences

Commons

Right click to open a feedback form in a new tab to let us know how this document benefits you.

\section{Repository Citation}

Brown, Joshua D.; Raissi, Driss; Han, Qiong; Adams, Val R.; and Talbert, Jeffery, "Vena Cava Filter Retrieval Rates and Factors Associated with Retrieval in a Large US Cohort" (2017). Pharmacy Practice and Science Faculty Publications. 35.

https://uknowledge.uky.edu/pps_facpub/35

This Article is brought to you for free and open access by the Pharmacy Practice and Science at UKnowledge. It has been accepted for inclusion in Pharmacy Practice and Science Faculty Publications by an authorized administrator of UKnowledge. For more information, please contact UKnowledge@lsv.uky.edu. 


\section{Vena Cava Filter Retrieval Rates and Factors Associated with Retrieval in a Large US Cohort}

Digital Object Identifier (DOI)

https://doi.org/10.1161/JAHA.117.006708

Notes/Citation Information

Published in Journal of the American Heart Association, v. 6, issue 9, e006708, p. 1-11.

(c) 2017 The Authors.

This is an open access article under the terms of the Creative Commons

Attribution-NonCommercial-NoDerivs License, which permits use and distribution in any medium, provided the original work is properly cited, the use is non-commercial and no modifications or adaptations are made.

This article is available at UKnowledge: https://uknowledge.uky.edu/pps_facpub/35 


\title{
Vena Cava Filter Retrieval Rates and Factors Associated With Retrieval in a Large US Cohort
}

\author{
Joshua D. Brown, PharmD, PhD; Driss Raissi, MD; Qiong Han, MD, PhD; Val R. Adams, PharmD; Jeffery C. Talbert, PhD
}

Background-Retrieval of vena cava filters (VCFs) is important for safety as complications increase with longer dwell times. This study assessed VCF retrieval rates and factors associated with retrieval in a national cohort.

Methods and Results-VCFs were identified by procedural codes from an administrative claims database. Patients were identified who had a VCF placement during a hospitalization from a national commercial administrative claims database. Indications for VCF placement were identified as pulmonary embolism with or without deep vein thrombosis, deep vein thrombosis only, or prophylactic. Patient demographic and clinical characteristics were included in proportional hazard regression models to find associations with early (90-day) and 1-year VCF retrieval. Initiation of anticoagulation and the correlation between time-to-retrieval and time-to-initiation of anticoagulation were observed. Of 54766 patients receiving a VCF, 36.9\% had pulmonary embolism, 43.9\% had deep vein thrombosis only, and 19.2\% had no apparent venous thromboembolism present. Over the 1 year of follow-up, the cumulative incidence of VCF retrieval was $18.4 \%$. Retrieval increased over time from a low of $14.0 \%$ in 2010 up to $\approx 24 \%$ in 2014. In adjusted time-to-event models, increasing age, differing regions, and some comorbidities were associated with poorer retrieval rates. Initiation of anticoagulation was poorly correlated with retrieval, with anticoagulation preceding retrieval by a median of 51 days while those without retrieval had a median of 278 days of exposure to anticoagulation.

Conclusions-VCF retrieval increased over the study period but remained suboptimal and was weakly correlated with anticoagulation initiation. (J Am Heart Assoc. 2017;6:e006708. DOI: 10.1161/JAHA.117.006708.)

Key Words: pulmonary embolism • retrieval device • vena cava • vena cava filter • venous thromboembolism

$\mathrm{V}$ ena cava filters (VCFs) are used to mechanically prevent thrombi from migrating to the pulmonary circulation. Generally, VCFs are reserved for patients who have absolute or relative contraindications to anticoagulation and who are at a high risk of recurrent venous thromboembolism (VTE). ${ }^{1-3}$ With the advent of retrievable VCFs, there has been a marked increase in overall use. ${ }^{4-6}$ Retrievable VCFs differ in that they can be removed once contraindications have subsided and patients can be initiated on anticoagulation.

In real-world settings, retrieval rates of VCFs have been dismal, with reports ranging from $10 \%$ to $50 \%$ and an estimated

From the Department of Pharmacy Practice and Science, University of Kentucky College of Pharmacy, Lexington, KY (J.D.B., V.R.A., J.C.T.); Department of Pharmaceutical Outcomes and Policy, University of Florida College of Pharmacy, Gainesville, FL (J.D.B.); Division of Vascular and Interventional Radiology, Department of Radiology, University of Kentucky College of Medicine, Lexington, KY (D.R., Q.H.).

Correspondence to: Joshua D. Brown, PharmD, PhD, 1225 Center Dr, HPNP Room 3320, Gainesville, FL. E-mail: joshua.brown@ufl.edu

Received May 20, 2017; accepted August 1, 2017.

(C) 2017 The Authors. Published on behalf of the American Heart Association, Inc., by Wiley. This is an open access article under the terms of the Creative Commons Attribution-NonCommercial-NoDerivs License, which permits use and distribution in any medium, provided the original work is properly cited, the use is non-commercial and no modifications or adaptations are made. average near $30 \%{ }^{7,8}$ Poor retrieval rates correspond to an increase in reported adverse events. ${ }^{7}$ Complications associated with VCFs include increased risk of deep vein thrombosis (DVT), inferior vena cava thrombosis, inferior vena cava penetration, VCF fracture, and VCF embolization. ${ }^{7,9-11}$ Given these trends, the US Food and Drug Administration has issued a safety communication highlighting the need to remove VCFs once the risk of pulmonary embolism (PE) has subsided based on modeling studies showing that VCFs are most clinically beneficial if retrieved within 90 days after implantation. ${ }^{11,12}$

Given the continued growth in VCF use and the variation that has been observed between institutions, ${ }^{13-17}$ assessment of what factors drive retrieval rates and timing of anticoagulation on a national scale is needed to evaluate clinical practice. ${ }^{18}$ This study sought to evaluate the trend in retrieval rates and patient factors associated with retrieval as well as the association between retrieval and anticoagulation. While retrieval rates were expected to increase over time, we hypothesized differential retrieval based on indication and patient characteristics. Furthermore, we hypothesized there would be a weak association between retrieval and anticoagulation, although treatment with anticoagulation generally indicates there would no longer be a continued need for an indwelling VCF. 


\section{Clinical Perspective}

\section{What Is New?}

- This is the first known study to examine retrieval rates for vena cava filters (VCFs) in a national cohort.

- The results are consistent with prior meta-analyses of single institution retrieval rates showing about a $25 \%$ to $30 \%$ retrieval rate of all placed.

- Despite safety warnings for indwelling VCFs, most remained in place and were poorly correlated with initiation of anticoagulation.

- Retrieval rates were strongly dependent on age, with older patients less likely to have retrieval, patient residence, prophylactic indication for VCF placement (no thrombosis present), and having VCF placement in more recent years.

\section{What Are the Clinical Implications?}

- The US Food and Drug Administration has suggested that VCFs be removed once clinically appropriate to avoid complications.

- These warnings were in response to many reports of VCF failures including device fractures and penetration of the vena cava that were associated with indwell time.

- In order to maximize the net clinical benefit of VCFs, patients should be initiated on anticoagulation once contraindications have abated and VCFs should be removed.

- Utilization of VCFs and subsequent retrieval rates vary widely by geography, suggesting that institutions and clinics should evaluate their practices to better ensure patient safety.

\section{Methods}

\section{Data Source}

This observational cohort study utilized the Truven Health Analytics MarketScan database, which are administrative healthcare claims data including medical diagnostic and procedural information and pharmacy fill records billed to an individual's health insurance. The data include information for $\approx 40$ million unique individuals per year. The university's Institutional Review Board approved use of the data and waived the requirement for informed consent of participants given that the data are de-identified and collected for nonresearch purposes.

\section{Cohort Identification}

All patients during the years 2010 to 2014 who had a VCF placed were identified using Current Procedural Terminology (CPT: 37191, 37620, 35940) and International Classification of Diseases, 9th revision (ICD-9: 38.7) procedural codes. The indication for VCF was identified by ICD-9 diagnosis codes as
PE (415.1x) with or without DVT, DVT only (451.xx or 453.xx), or no apparent VTE (prophylactic). ${ }^{19,20}$ To increase the validity of these indication diagnoses, only the primary diagnosis field was used. For inclusion, patients were required to be 18 years old or older and have a minimum of 6 months of eligibility in the database before VCF placement.

\section{Cohort Characteristics}

Demographic variables included age, sex, geographic region, and residence status. Age was divided into 18 to 34,35 to 44 , 45 to 54,55 to 64,65 to 74 , and 75 and older categories. Geographic region included US census regions (Northeast, North Central, South, West, and unknown) and residence status was divided into urban or rural. Insurance status was classified as commercial or Medicare, fully or partially capitated, and assignment to a primary care provider (PCP).

Conditions and procedures present during VCF implantation were recorded. Concurrent bleeding, unstable condition, sepsis or septic shock, infection, anemia, trauma, and pregnancy were all recorded using ICD-9 diagnosis codes. ${ }^{13,20}$ Patients receiving thrombolytic therapy, embolectomy procedures, or major surgery were identified using a combination of procedural codes. ${ }^{21}$ Patients who died during the hospitalization during which the VCF was placed were also noted. Comorbid conditions observed in the pre-index period consisted of Charlson comorbidities along with a Charlson Comorbidity Index, which represents the overall "comorbidity burden" widely used for risk adjustment. ${ }^{22,23}$

\section{Outcome Events}

The primary outcome was VCF retrieval identified by CPT (37 193, 37 203) and ICD-9 (38.7) procedure codes. Given that the ICD-9 procedure code for placement and retrieval is the same, retrievals for those patients only having the ICD-9 procedure code present had to be on separate days to record retrieval. However, since CPT codes and not ICD-9 codes are used for billing purposes, patients lacking the CPT codes were the exception, with $>95 \%$ of all patients having CPT codes recorded. Patients were followed forward from the VCF placement until the VCF was retrieved, they died, they were lost to follow-up, or the end of the study period. The 30-, 60-, 90-, 180-day, and 1-year cumulative incidence of VCF retrieval was estimated using Fine and Gray's time-to-event, survival analysis methodology, accounting for death as a competing risk. ${ }^{24}$ Time to VCF retrieval was also reported.

\section{Time to Anticoagulation Initiation}

Anticoagulation initiation was assessed as the first outpatient prescription for an injectable (dalteparin, enoxaparin, 
tinzaparin, fondaparinux) or oral (warfarin, dabigatran, rivaroxaban, apixaban) anticoagulant. Those with prophylactic indications ("no VTE") were excluded as they might not have indications for anticoagulation on discharge. Furthermore, those who had VCF retrieval before discharge were excluded. Time to anticoagulation was compared with the time to retrieval and described for those who did not have retrieval during follow-up. Time for both events was calculated based on the date of discharge from a hospitalization since the filled prescriptions data would not be available until hospital discharge occurred.

\section{Time-to-Event Analysis}

To identify factors associated with VCF retrieval, we developed a Cox proportional hazards model including patient characteristics. The proportionality assumption for all variables was evaluated for using Schoenfeld residuals as well as using time as an interaction term for each variable. Both methods showed that this assumption held true. Because of collinearity with age, Medicare or commercial insurance status was excluded in the model. Two models were estimated predicting 90-day and 1-year retrieval. The 90-day time point was chosen to represent "early retrievals" and was consistent with a prior modeling study showing higher net clinical benefit if removed in $<90$ days. ${ }^{11}$ Patients who had not had retrieval or had not died at the end of the 90-day or 365-day period were censored. Hazard ratios and their 95\% confidence intervals were estimated. All analyses were conducted using SAS Enterprise Guide version 7.1 (Cary, NC) with significance level of $\alpha=0.05$ for all statistical analyses.

\section{Results}

\section{Patient Characteristics}

During 2010 to 2014, 54766 patients received a VCF and met the eligibility requirements to be included in the study. Of these, $36.9 \%$ presented with a PE, $43.9 \%$ with DVT alone, and 19.2\% had no apparent VTE present (Table 1). The mean (SD) age of the cohort was 65 (16) years old, $51 \%$ were female, and they were geographically diverse with nearly $85 \%$ residing in urban areas. Insurance details included $13.9 \%$ of the cohort having a primary care provider and $8.6 \%$ having insurance with full or partial capitated payments. A total of 1628 (3.0\%) of the cohort died during the initial hospitalization and were not included in subsequent analyses.

Overall, $14.3 \%(\mathrm{~N}=7619)$ of the cohort who survived the index hospitalization had the VCF retrieved within 1 year and $8 \%(\mathrm{~N}=4228)$ died (Table 2). For those who had retrieval, the mean (SD) time to retrieval was 93 (78) days, with a median of 71 days and interquartile range (IQR) of 35 to 130 days. Those with PE had the highest mean and median times to retrieval (101 and 81 days) compared with those with DVT only (91 and 68 days) and compared with those with no VTE $(83$ and 61 days, $P<0.001$ for all comparisons).

Figure 1 shows the cumulative incidence of VCF retrieval by the index indication and Table 3 shows the cumulative incidence for selected variables. At 1 year, retrieval was highest for those with no VTE on index, reaching nearly $25 \%$ (23.9-25.8\%). Retrieval increased with each year of study, going from $14.0 \%(13.3-14.7 \%$ ) in 2010 up to $38.2 \%$ (19.4-57.0\%, skewed by low follow-up time) in 2014 $(P<0.001$ for trend excluding 2014 data). Data from 2014 allowed for smaller sample size for 1-year of follow-up. However, trends were consistent across smaller time frames for 2014 and showed a year-over-year increase in retrieval at all time points. Differences in retrieval between age groups were significant, with younger age groups having higher retrieval. For example, those aged 18 to 34 had 1-year retrieval of $42.8 \%$ (40.4-45.2\%) while retrieval in those 75 years old and older was just $5.4 \%$ (5.0-5.8\%, $P<0.001)$.

\section{Factors Related to Retrieval}

In fully adjusted analyses (Table 4), age remained significantly associated with VCF retrieval at both 90 days and 365 days of follow-up, although the association was much stronger for the 1-year model. Patients with no VTE were more likely to have retrieval compared with those with DVT only, and there was no difference in retrieval between those with PE compared with those with DVT. Geographic region was also significant, with those residing in the North Central (90 days and 1 year) and West ( 1 year only) regions being more likely to have retrieval compared with those in the Northeast.

Year of filter placement was modeled both as a covariate as well as used to stratify the analysis. In stratified analysis, no differences were observed between the covariates and their association with VCF retrieval compared with the base model with year as a covariate. As a covariate, each year of VCF placement was associated with increased 90-day and 1-year retrieval compared with year 2010. For the final year 2014 , this corresponded to nearly a 2-fold difference in retrieval rate compared with 2010 (hazard ratio $=1.90,95 \%$ confidence interval, 1.76-2.06).

\section{Time to Anticoagulation}

During follow-up, the data set had follow-up prescription information for 37272 persons in the cohort with DVT/PE 
Table 1. Demographic and Clinical Characteristics of Patients Receiving VCFs by Indication

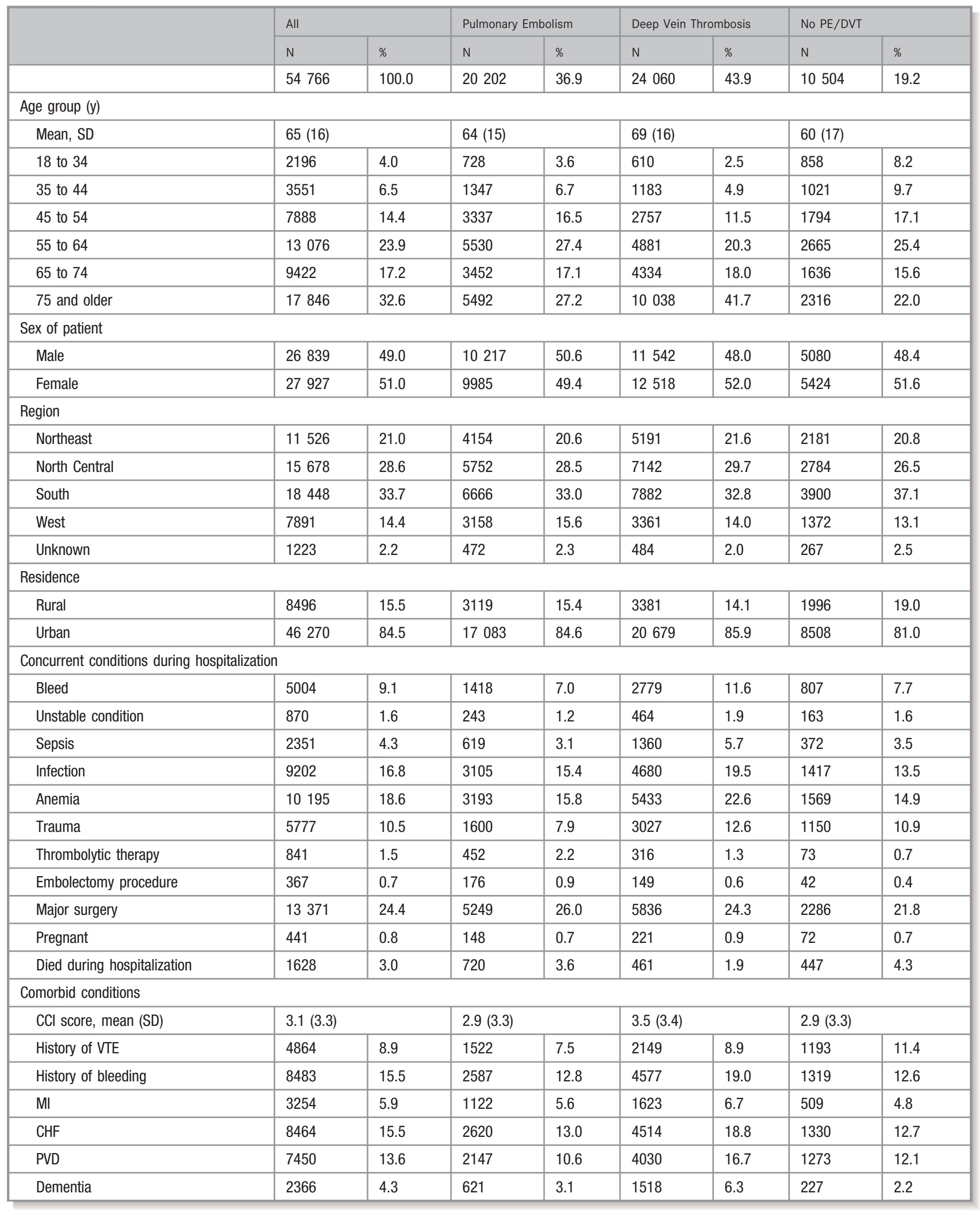


Table 1. Continued

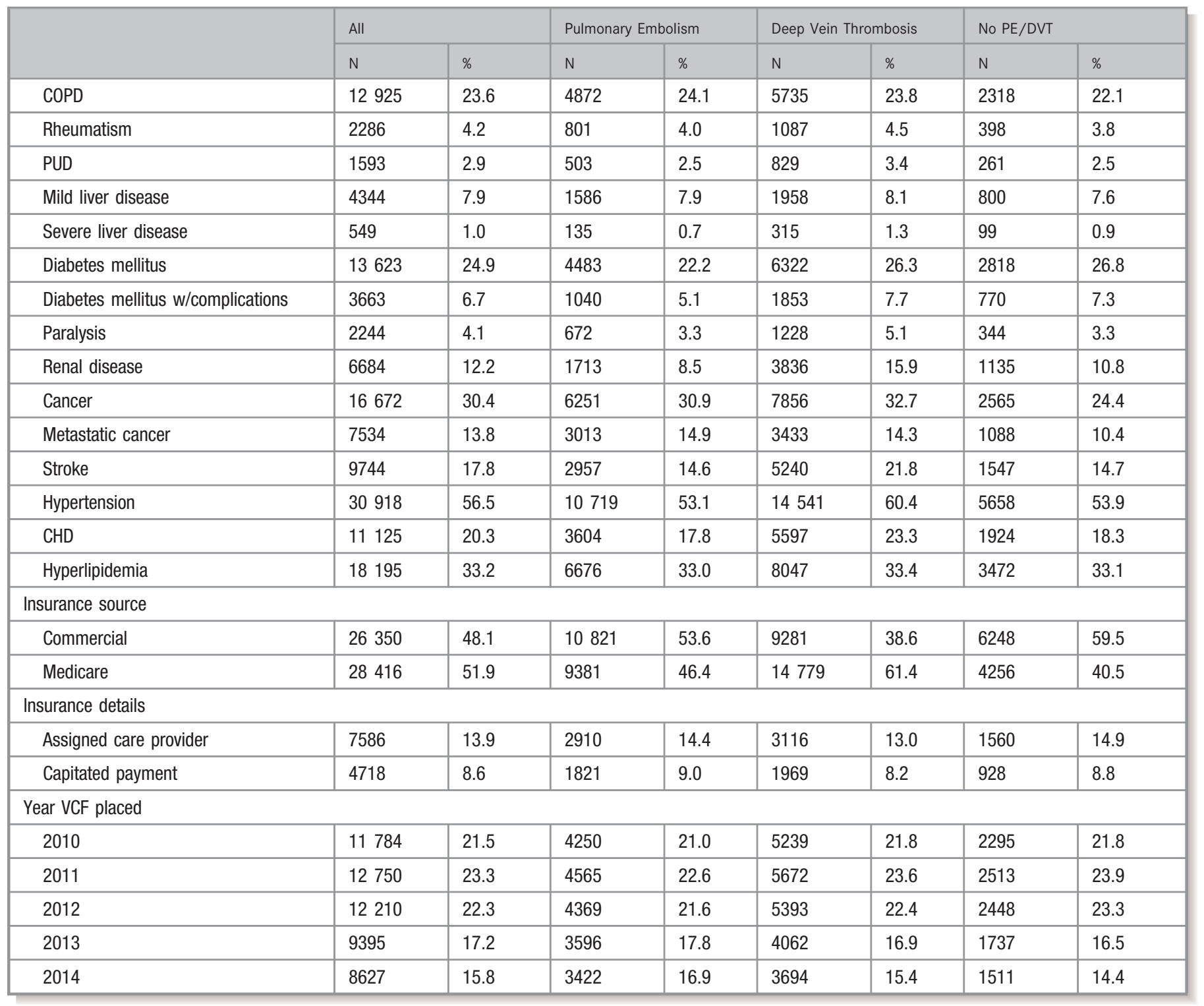

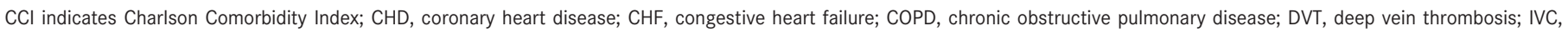

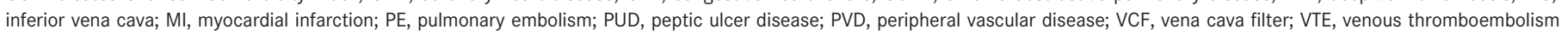

indications and who did not have retrieval before discharge. Among these, 23510 (63.1\%) initiated anticoagulation including $61 \%$ who never had retrieval, $79.2 \%$ among those with retrieval, and $47.8 \%$ among those who died, with median time to initiation of 17 (IQR 6-50) days. Initiation of anticoagulation differed significantly for those who eventually had retrieval ( $\mathrm{N}=4729$, median 11 , IQR 5-31 days) and those who did not have retrieval ( $\mathrm{N}=17$ 628, median 17, IQR 6-50 days, $P<0.001)$. Overall, time to anticoagulation and time to retrieval were poorly correlated, with anticoagulation preceding retrieval by a median of 51 (IQR 13-110) days and $R^{2}=0.06$ (Figure 2). For those who never had retrieval, there was a median of 278 (IQR 98-
350) days of anticoagulation treatment during the 1-year follow-up period.

\section{Discussion}

In PREPIC2 (Prevention du Risque d'Embolie Pulmonaire par Interruption Cave 2), the only randomized trial for retrievable VCFs, the retrieval rate was $>90 \%$ with a dedicated 3-month follow-up visit. ${ }^{25}$ However, in real-world practice, estimates of the retrieval rates range much lower, with an average of about one third of all VCFs eventually being retrieved. ${ }^{7}$ Patients are at risk for complications including inferior vena cava thrombosis, device fracture, device migration, and DVT so long as 
Table 2. Outcomes of Patients Receiving VCFs At 1 Year of Follow-Up

\begin{tabular}{|c|c|c|c|c|c|c|c|c|}
\hline & \multicolumn{2}{|l|}{ Overall } & \multicolumn{2}{|l|}{ PE } & \multicolumn{2}{|l|}{ DVT } & \multicolumn{2}{|c|}{ No VTE } \\
\hline \multicolumn{9}{|l|}{ Outcome } \\
\hline VCF retrieval & 7619 & $(14.3 \%)$ & 2884 & $(14.8 \%)$ & 2686 & $(11.4 \%)$ & 2049 & (20.4\%) \\
\hline Censored & 41291 & $(77.7 \%)$ & 14971 & $(76.8 \%)$ & 18963 & $(80.4 \%)$ & 7357 & (73.2\%) \\
\hline \multicolumn{9}{|l|}{ Follow-up time } \\
\hline Median, IQR & \multicolumn{2}{|l|}{$186(56-365)$} & \multicolumn{2}{|l|}{$188(58-365)$} & \multicolumn{2}{|l|}{$187(54-365)$} & \multicolumn{2}{|c|}{$176(56-365)$} \\
\hline \multicolumn{9}{|l|}{ Time to retrieval } \\
\hline Mean, SD & \multicolumn{2}{|l|}{$93(78)$} & \multicolumn{2}{|l|}{$101(81)$} & \multicolumn{2}{|l|}{$91(79)$} & \multicolumn{2}{|c|}{$83(73)$} \\
\hline Median, IQR & \multicolumn{2}{|l|}{$71(35-130)$} & \multicolumn{2}{|l|}{$81(38-143)$} & \multicolumn{2}{|l|}{$68(33-132)$} & \multicolumn{2}{|c|}{$61(32-113)$} \\
\hline \multicolumn{9}{|l|}{ Time to death } \\
\hline
\end{tabular}

DVT indicates deep vein thrombosis; IQR, interquartile range; PE, pulmonary embolism; VCF, vena cava filter; VTE, venous thromboembolism.

the VCF remains in place. ${ }^{7,26}$ One study found that there is an optimal net clinical benefit if a VCF is retrieved within 29 to 54 days after placement in prophylactic indications, which remained in favor of VCFs up to 180 days postimplantation. ${ }^{11}$ That article was referenced by a US Food and Drug Administration safety communication, which responded to multiple reports of complications with VCFs and increasing publicity through litigation and media. ${ }^{12}$
The current analysis is consistent with other reports regarding VCF retrieval. ${ }^{7,8}$ The retrieval rate increased over time, from roughly every 1-out-7 VCFs being retrieved in 2010 up to 1 -out-4 retrieved in 2014 . This effect may be explained by the increased attention VCFs received over this time period including US Food and Drug Administration safety alerts, as well as guideline updates (American College of Chest Physicians), ${ }^{1}$ which called for more conservative use of VCFs

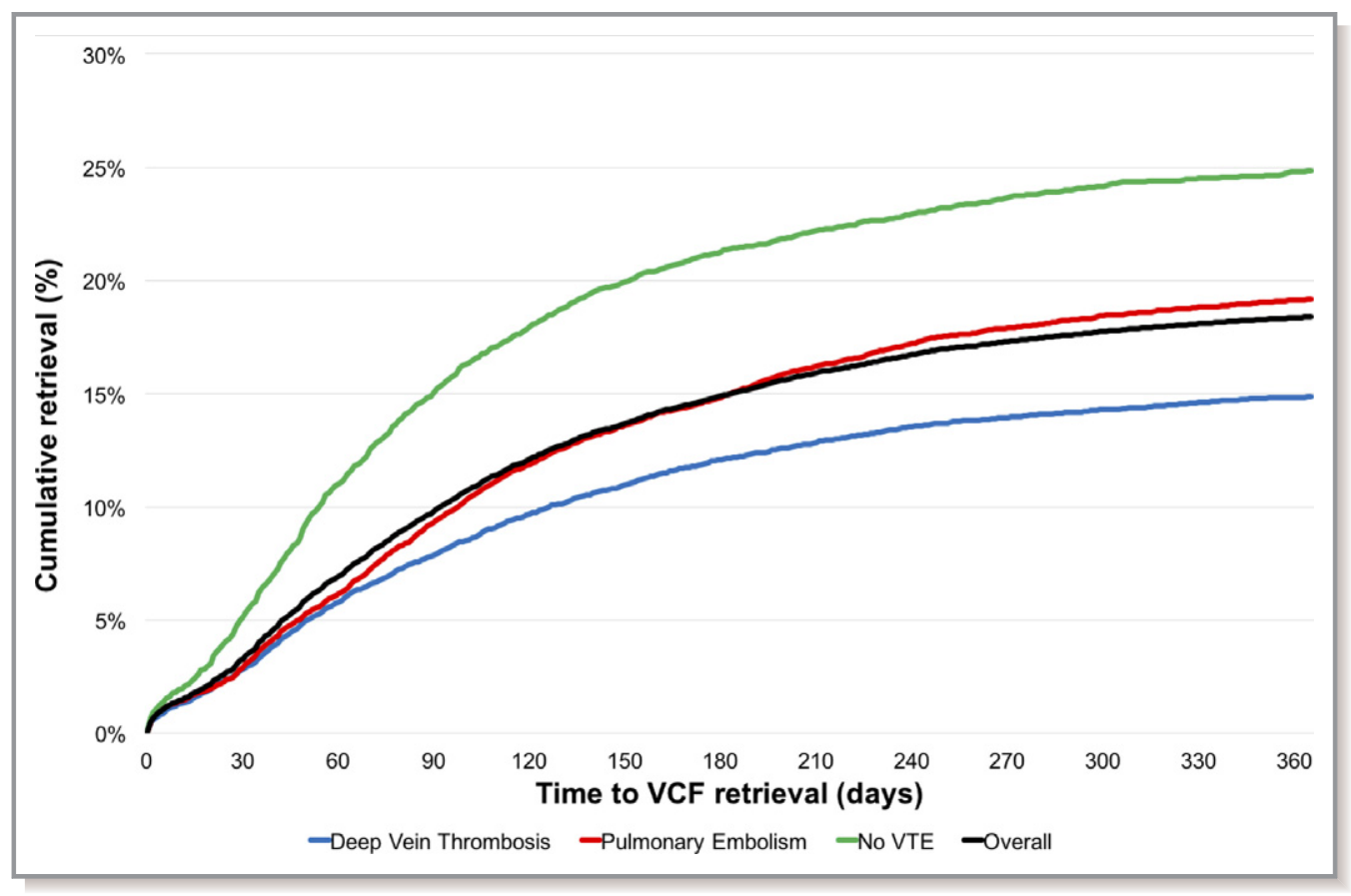

Figure 1. Cumulative incidence of vena cava filter (VCF) retrieval by indication over 1-y of follow-up accounting for death as a competing risk. VTE indicates venous thromboembolism. 
Table 3. Cumulative Incidence and 95\% Confidence Interval of Inferior VCF Retrieval at Time Intervals by Key Demographic and Clinical Factors

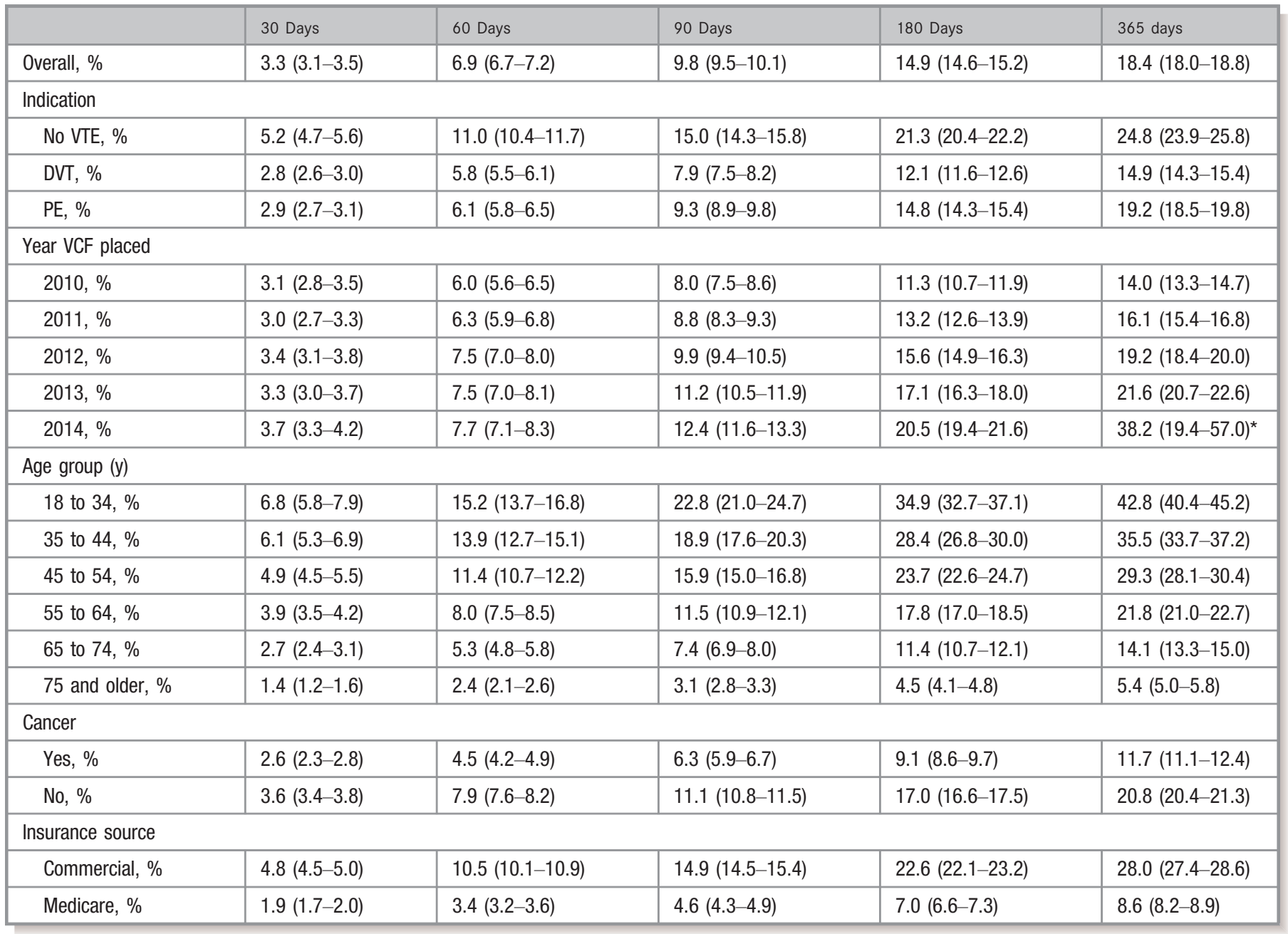

DVT indicates deep vein thrombosis; VCF, vena cava filter; PE, pulmonary embolism; VTE, venous thromboembolism.

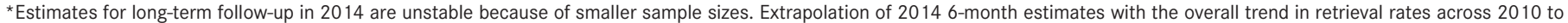
2014 produce a retrieval estimate of $23 \%$ to $25 \%$.

compared with guidelines presented by other physician societies in interventional radiology and trauma. ${ }^{27,28}$ For those who did have their VCF retrieved in our study, time to retrieval was within mean and median times of 93 and 71 days postimplantation. However, retrieval was poorly correlated with anticoagulation initiation.

Several patient-related factors were also associated with retrieval, including demographic and clinical characteristics. Increasing age of the patient was associated with lower retrieval, which likely contributed to perceived ongoing risk of PE or a desire to not treat older individuals with anticoagulation. Region of residence was also strongly associated with retrieval, which may indicate regional practice differences as well as differences in patient demography. Patients living in an urban setting were more likely to have their filter retrieved as well, suggesting that patients being referred to a distant medical center for VCF placement may have limited follow-up for retrieval. Among patient comorbidities, those considered prothrombotic (eg, cancer, stroke, hyperlipidemia, myocardial infarction) and related to bleeding (eg, liver disease) were associated with lower retrieval.

Other studies investigating factors associated with retrieval rates have focused on poor patient follow-up as the primary reason VCFs are not removed. ${ }^{29-33}$ Patient follow-up is generally left to the referring or primary physician, with some studies showing improved retrieval if the responsibility of follow-up is placed on the implanting physician instead. ${ }^{32-34}$ In institutions where the implanting physicians are made responsible for patient follow-up, retrieval rates have increased from $24 \%$ to $59 \%$ and $29 \%$ to $60 \% .^{32,33}$

While there is inherent concern for patient safety associated with these low retrieval rates, clinical practices are also financially incentivized to increase retrieval of VCFs. One study showed that because of the increased cost between 
Table 4. Regression Results Showing Patient Factors Associated With 90-D (Early) Retrieval and 1-Year Retrieval

\begin{tabular}{|c|c|c|c|c|c|c|}
\hline & \multicolumn{3}{|c|}{ 90-D Retrieval } & \multicolumn{3}{|c|}{ 1-Y Retrieval } \\
\hline \multicolumn{7}{|l|}{ Age group (y) } \\
\hline 35 to 44 & 0.97 & 0.94 & 1.00 & 0.88 & 0.80 & 0.97 \\
\hline 45 to 54 & 0.95 & 0.92 & 0.98 & 0.79 & 0.72 & 0.86 \\
\hline 65 to 74 & 0.87 & 0.84 & 0.89 & 0.41 & 0.37 & 0.45 \\
\hline 75 and older & 0.82 & 0.80 & 0.84 & 0.17 & 0.15 & 0.19 \\
\hline \multicolumn{7}{|l|}{ Sex } \\
\hline Male & Ref. & Ref. & Ref. & Ref. & Ref. & Ref. \\
\hline \multicolumn{7}{|l|}{ Region } \\
\hline North Central & 1.03 & 1.02 & 1.04 & 1.29 & 1.20 & 1.38 \\
\hline South & 0.99 & 0.98 & 1.00 & 0.89 & 0.83 & 0.95 \\
\hline West & 1.10 & 1.09 & 1.12 & 1.89 & 1.76 & 2.04 \\
\hline Unknown & 1.01 & 0.98 & 1.04 & 1.24 & 1.05 & 1.46 \\
\hline \multicolumn{7}{|l|}{ Residence } \\
\hline Rural & Ref. & Ref. & Ref. & Ref. & Ref. & Ref. \\
\hline Urban & 1.01 & 1.00 & 1.02 & 1.13 & 1.06 & 1.21 \\
\hline \multicolumn{7}{|l|}{ Index VTE } \\
\hline Sepsis & 1.00 & 0.98 & 1.01 & 0.92 & 0.76 & 1.12 \\
\hline Infection & 0.98 & 0.97 & 0.99 & 0.84 & 0.76 & 0.91 \\
\hline Anemia & 0.99 & 0.98 & 0.99 & 0.91 & 0.84 & 0.98 \\
\hline Trauma & 0.99 & 0.98 & 1.00 & 1.00 & 0.92 & 1.09 \\
\hline Thrombolytic therapy & 1.06 & 1.02 & 1.09 & 1.29 & 1.11 & 1.49 \\
\hline Embolectomy procedure & 1.00 & 0.96 & 1.04 & 0.89 & 0.68 & 1.17 \\
\hline Major surgery & 0.98 & 0.97 & 0.99 & 0.92 & 0.87 & 0.97 \\
\hline Pregnant & 1.05 & 0.99 & 1.11 & 1.36 & 1.15 & 1.60 \\
\hline \multicolumn{7}{|c|}{ Comorbid conditions during pre-index look back } \\
\hline CCI score (per 1 unit) & 1.00 & 0.99 & 1.01 & 0.97 & 0.90 & 1.05 \\
\hline History of VTE & 1.03 & 1.02 & 1.04 & 1.17 & 1.08 & 1.26 \\
\hline History of bleeding & 0.98 & 0.97 & 0.99 & 0.77 & 0.67 & 0.87 \\
\hline Myocardial infarction & 0.99 & 0.98 & 1.00 & 0.82 & 0.71 & 0.96 \\
\hline Heart failure & 0.98 & 0.97 & 0.99 & 0.67 & 0.60 & 0.74 \\
\hline Peripheral vascular disease & 0.99 & 0.98 & 1.00 & 0.85 & 0.77 & 0.94 \\
\hline
\end{tabular}


Table 4. Continued

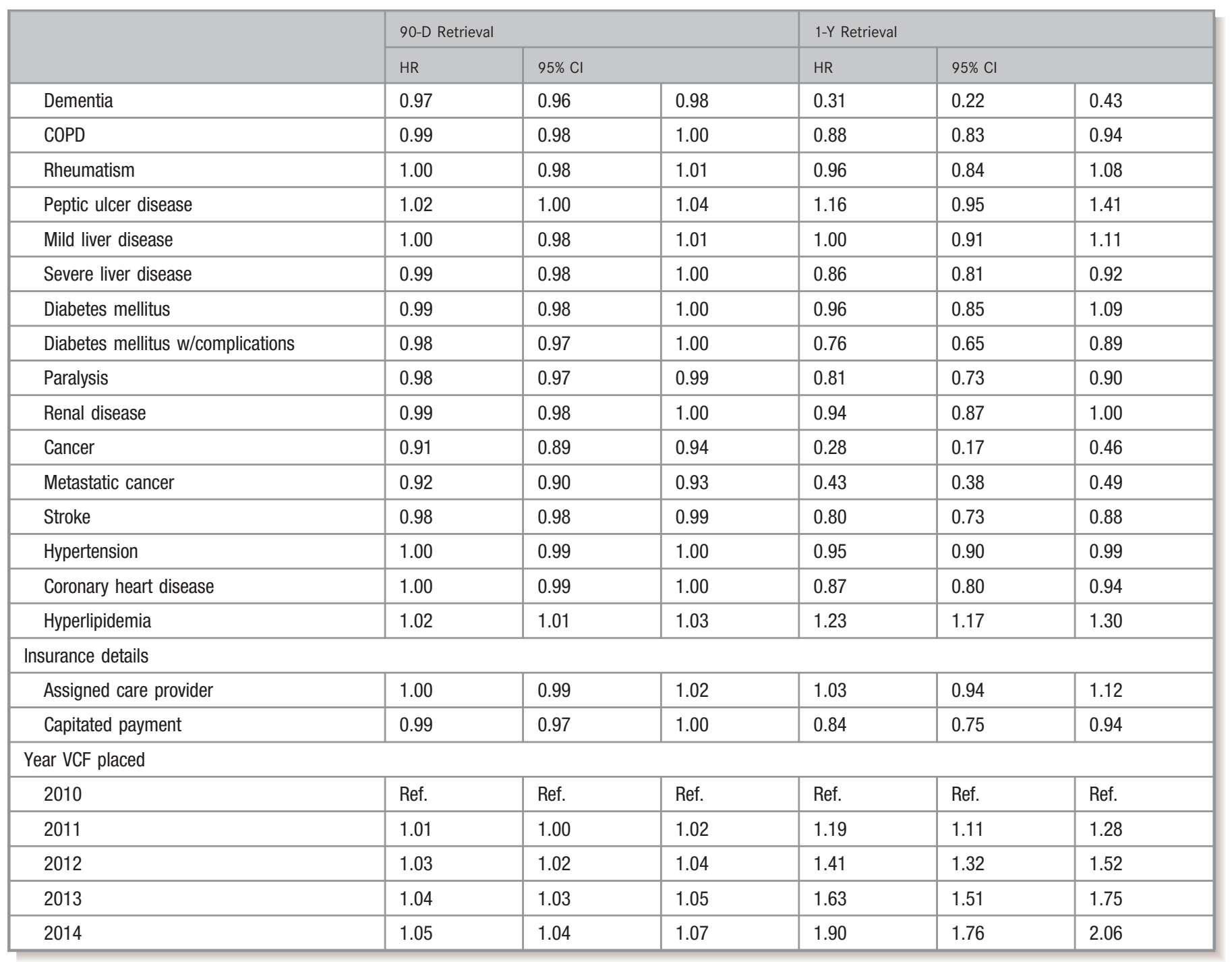

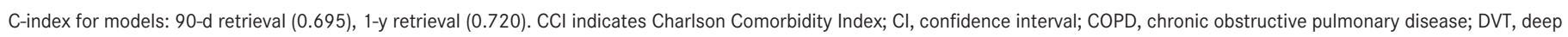
vein thrombosis; HR, hazard ratio; PE, pulmonary embolism; VTE, venous thromboembolism.

retrievable and permanent devices, retrievable devices are only cost-effective in interventional radiology clinics if at least $40 \%$ are eventually retrieved, driven by separate billable procedure codes for implantation and retrieval. ${ }^{34}$ Even without the cost differential between permanent and retrievable devices, it is inherent that clinic revenue will be increased with improved patient follow-up, management, and retrieval. At least 1 study at a single institution evaluated the financial feasibility of implementing a quality improvement initiative within their clinical practice. ${ }^{35}$ They compared baseline retrieval rates with those achieved by issuing letters to patients and then with those achieved with prospective follow-up of patients. Overall, their retrieval rates increased from $8 \%$ to $40 \%$ with mailed letters to retrospective patients, and increased further up to $52 \%$ with prospective follow-up of new patients. Although improving VCF retrieval requires a shift in patient management, retrieval will improve patient outcomes and provides financial incentive to the clinic.

\section{Limitations}

This study has limitations inherent to all studies utilizing administrative claims data. ${ }^{36,37}$ Most notably, detailed clinical data are not available, which may have impacted the study results. Procedural codes were utilized to identify VCF placement; however, these codes are not specific to permanent or retrievable devices. As of 2006, retrievable devices made up about $85 \%$ of the VCF market in the United States, which likely increased to $>90 \%$ since then. ${ }^{38-41}$ Therefore, the retrieval estimates presented here are underestimated. Assuming that $10 \%$ to $20 \%$ of all VCFs used are permanent and thus cannot be retrieved, this would make 


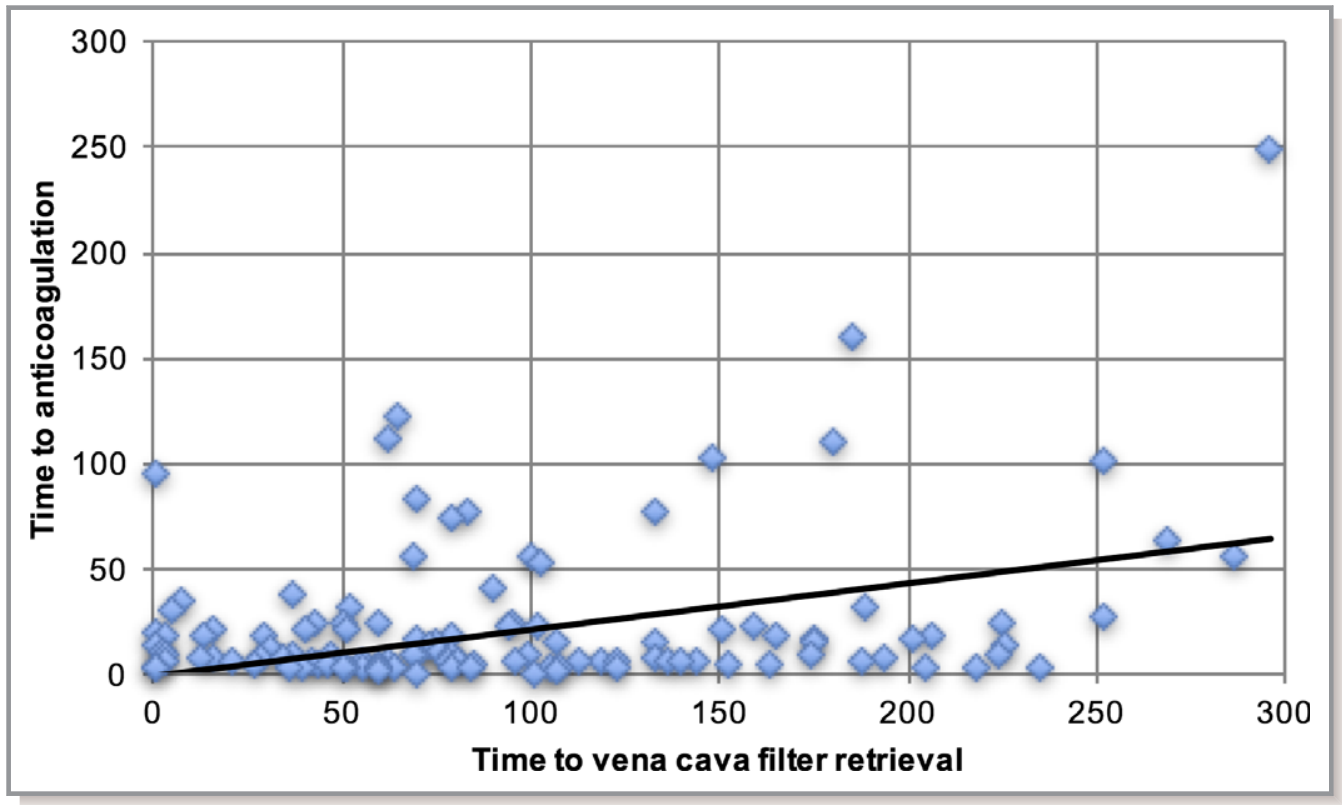

Figure 2. Plot of times to outpatient anticoagulation and vena cava filter retrieval. Black line represents the fit of the data. Time is based on follow-up after the discharge date from the hospitalization where the VCF was placed. Those with prophylactic indications and those with retrieval before discharge are excluded. $R^{2}=0.06$. VCF indicates vena cava filter.

our estimated retrieval $\approx 26 \%$ to $30 \%$, making this corrected estimate near previous estimates of national retrieval rates of $\approx 30 \%{ }^{6,7}$

We allowed enrollment of patients in 2014, but those enrolled later in 2014 would have limited follow-up, which skewed the estimates of cumulative retrieval at 365 days. However, the increasing trend in retrieval rates is stable across estimates at earlier time points $(30,60,90$, and 180 days) in 2014. Extrapolating these stable estimates from 180 days to 365 days across all years shows a trend increasing year-to-year of $+2 \%$ to $4 \%$. Therefore, we have estimated that with perfect follow-up for those enrolled in 2014 , the retrieval estimate would be nearer $23 \%$ to $25 \%$.

It is unclear how selection of retrievable versus permanent devices would differ between, for example, older versus younger patients or in cancer patients with poor prognosis, adding some uncertainty to the comparison of retrieval between certain relevant groups. However, in contemporary patients, use of retrievable VCFs (also referred to as "optional" VCFs because they can be left permanently or retrieved when clinically indicated) may be a more preferred therapeutic option allowing for flexibility in care versus nonretrievable alternatives. Thus, while there may be a differential influence of this limitation, the results are still interpretable to identify patient subgroups that are less likely to receive, as well as to not have retrieval of, retrievable VCFs. Therefore, the trend showing an increase in retrieval rates likely indicates both a trend in uptake of retrievable VCFs as well as increased retrieval rates. More work will be needed with detailed clinical data to determine differences in selection of permanent versus retrievable treatment options. Lastly, routine medications administered during a hospital stay are often omitted from billing records because of capitated payment systems. Thus, we did not attempt to observe use of anticoagulation during the hospital stay because it would be unreliably reported or unreported.

\section{Conclusion}

In this national study of VCF retrieval, less than 1 of every 4 filters was retrieved within 1 year. Retrieval rates differ based on patient characteristics but increased over the study time period (2010-2014), while retrieval and initiation of anticoagulation were poorly correlated. Physicians should consider ongoing indications for indwelling VCFs and timing of retrieval with anticoagulation initiation throughout follow-up to optimize patient care.

\section{Sources of Funding}

The project described was supported by the National Center for Advancing Translational Sciences, National Institutes of Health, through grant number UL1TR000117. The content is solely the responsibility of the authors and does not necessarily represent the official views of the NIH. Drs. Brown and 
Adams were supported by a research grant from the Hematology/Oncology Pharmacists Association.

\section{Disclosures}

None.

\section{References}

1. Kearon C, AkI EA, Ornelas J, Blaivas A, Jimenez D, Bounameaux H, Huisman M, King CS, Morris TA, Sood N. Antithrombotic Therapy for VTE disease. Chest. 2016;149:315-352.

2. Kaufman JA, Kinney TB, Streiff MB, Sing RF, Proctor MC, Becker D, Cipolle M, Comerota AJ, Millward SF, Rogers FB. Guidelines for the use of retrievable and convertible vena cava filters: report from the Society of Interventional Radiology multidisciplinary consensus conference. I Vasc Interv Radiol. 2006;17:449-459.

3. Kaufman JA, Rundback JH, Kee ST, Geerts W, Gillespie D, Kahn SR, Kearon C, Rectenwald J, Rogers FB, Stavropoulos SW. Development of a research agenda for inferior vena cava filters: proceedings from a multidisciplinary research consensus panel. J Vasc Interv Radiol. 2009;20:697-707.

4. Stein PD, Kayali F, Olson RE. Twenty-one-year trends in the use of inferior vena cava filters. Arch Intern Med. 2004;164:1541-1545.

5. Stein PD, Matta F, Hull RD. Increasing use of vena cava filters for prevention of pulmonary embolism. Am J Med. 2011;124:655-661.

6. Desai SS, Naddaf A, Pan J, Hood D, Hodgson KJ. Impact of consensus statements and reimbursement on vena cava filter utilization. J Vasc Surg. 2016;64:425-429.

7. Angel LF, Tapson V, Galgon RE, Restrepo MI, Kaufman J. Systematic review of the use of retrievable inferior vena cava filters. J Vasc Interv Radiol. 2011;22:1522-1530.e3.

8. Friedell ML, Nelson PR, Cheatham ML. Vena cava filter practices of a regional vascular surgery society. Ann Vasc Surg. 2012;26:630-635.

9. Group PS. Eight-year follow-up of patients with permanent vena cava filters in the prevention of pulmonary embolism: the PREPIC (Prevention du Risque d'Embolie Pulmonaire par Interruption Cave) randomized study. Circulation. 2005; 112:416-422.

10. Durack JC, Westphalen AC, Kekulawela S, Bhanu SB, Avrin DE, Gordon RL, Kerlan RK. Perforation of the IVC: rule rather than exception after longer indwelling times for the Gunther Tulip and Celect retrievable filters. Cardiovasc Intervent Radiol. 2012;35:299-308.

11. Morales JP, Li X, Irony TZ, Ibrahim NG, Moynahan M, Cavanaugh KJ. Decision analysis of retrievable inferior vena cava filters in patients without pulmonary embolism. J Vasc Surg Venous Lymphat Disord. 2013;1:376-384.

12. US Food and Drug Administration. Removing retrievable inferior vena cava filters: FDA safety communication. Available at: http://www.fda.gov/Medica IDevices/Safety/AlertsandNotices/ucm396377.htm. Accessed April 15, 2016.

13. White RH, Geraghty EM, Brunson A, Murin S, Wun T, Spencer F, Romano PS. High variation between hospitals in vena cava filter use for venous thromboembolism. JAMA Intern Med. 2013;173:506-512.

14. Meltzer AJ, Graham A, Kim JH, Connolly PH, Karwowski JK, Bush HL, Meltzer EC, Schneider DB. Clinical, demographic, and medicolegal factors associated with geographic variation in inferior vena cava filter utilization: an interstate analysis. Surgery. 2013;153:683-688.

15. Dossett LA, Adams RC, Cotton BA. Unwarranted national variation in the use of prophylactic inferior vena cava filters after trauma: an analysis of the National Trauma Databank. J Trauma. 2011;70:1066-1070; discussion 10701071.

16. Brown JD, Talbert JC. Variation in the use of vena cava filters for venous thromboembolism in Hospitals in Kentucky. JAMA Surg. 2016;151:984-986.

17. Brown JD, Talbert JC. Hospital variation and patient characteristics associated with vena cava filter utilization. Med Care. 2017;55:31-36.

18. Siracuse JJ, Al Bazroon A, Gill HL, Meltzer AJ, Schneider DB, Parrack I, Jones DW, Connolly PH. Risk factors of nonretrieval of retrievable inferior vena cava filters. Ann Vasc Surg. 2015;29:318-321.

19. White RH, Garcia M, Sadeghi B, Tancredi DJ, Zrelak P, Cuny J, Sama P, Gammon H, Schmaltz S, Romano PS. Evaluation of the predictive value of ICD9-CM coded administrative data for venous thromboembolism in the United States. Thromb Res. 2010;126:61-67.
20. White RH, Zhou H, Kim J, Romano PS. A population-based study of the effectiveness of inferior vena cava filter use among patients with venous thromboembolism. Arch Intern Med. 2000;160:2033-2041.

21. Stein PD, Matta F, Alrifai A, Rahman A. Trends in case fatality rate in pulmonary embolism according to stability and treatment. Thromb Res. 2012;130:841-846.

22. Quan H, Sundararajan V, Halfon P, Fong A, Burnand B, Luthi JC, Saunders LD, Beck CA, Feasby TE, Ghali WA. Coding algorithms for defining comorbidities in ICD-9-CM and ICD-10 administrative data. Med Care. 2005;43:1130-1139.

23. Charlson ME, Charlson RE, Peterson JC, Marinopoulos SS, Briggs WM, Hollenberg JP. The Charlson comorbidity index is adapted to predict costs of chronic disease in primary care patients. J Clin Epidemiol. 2008;61:1234-1240.

24. Austin PC, Lee DS, Fine JP. Introduction to the analysis of survival data in the presence of competing risks. Circulation. 2016;133:601-609.

25. Mismetti P, Laporte S, Pellerin O, Ennezat PV, Couturaud F, Elias A, Falvo N, Meneveau N, Quere I, Roy PM, Sanchez O, Schmidt J, Seinturier C, Sevestre MA, Beregi JP, Tardy B, Lacroix P, Presles E, Leizorovicz A, Decousus H, Barral FG, Meyer G; Group PS. Effect of a retrievable inferior vena cava filter plus anticoagulation vs anticoagulation alone on risk of recurrent pulmonary embolism: a randomized clinical trial. JAMA. 2015;313:1627-1635.

26. Lee JK, So YH, Choi YH, Park SS, Heo EY, Kim DK, Chung HS. Clinical course and predictive factors for complication of inferior vena cava filters. Throm Res. 2014;133:538-543.

27. Caplin DM, Nikolic B, Kalva SP, Ganguli S, Saad WE, Zuckerman DA; SoIRSoP Committee. Quality improvement guidelines for the performance of inferior vena cava filter placement for the prevention of pulmonary embolism. J Vasc Interv Radiol. 2011;22:1499-1506.

28. Rogers FB, Cipolle MD, Velmahos G, Rozycki G, Luchette FA. Practice management guidelines for the prevention of venous thromboembolism in trauma patients: the EAST practice management guidelines work group. J Trauma. 2002;53:142-164.

29. Charlton-Ouw KM, Leake SS, Sola CN, Sandhu HK, Albarado R, Holcomb JB, Miller CC, Safi HJ, Azizzadeh A. Technical and financial feasibility of an inferior vena cava filter retrieval program at a level one trauma center. Ann Vasc Surg. 2015;29:84-89.

30. Davies R, Stanley J, Wickremesekera J, Khashram M. Retrieval rates of inferior vena cava (IVC) filters: are we retrieving enough? N Z Med J. 2015; 128:31-40.

31. Irwin E, Byrnes M, Schultz S, Chipman J, Beal A, Ahrendt M, Beilman G, Croston JK. A systematic method for follow-up improves removal rates for retrievable inferior vena cava filters in a trauma patient population. I Trauma. 2010;69:866-869.

32. Lynch FC. A method for following patients with retrievable inferior vena cava filters: results and lessons learned from the first 1100 patients. J Vasc Interv Radiol. 2011;22:1507-1512.

33. Minocha J, Idakoji I, Riaz A, Karp J, Gupta R, Chrisman HB, Salem R, Ryu RK, Lewandowski RJ. Improving inferior vena cava filter retrieval rates: impact of a dedicated inferior vena cava filter clinic. J Vasc Interv Radiol. 2010;21:18471851.

34. Janne d'Othée B, Faintuch S, Reedy AW, Nickerson CF, Rosen MP. Retrievable versus permanent caval filter procedures: when are they cost-effective for interventional radiology? J Vasc Interv Radiol. 2008;19:384-392.

35. Sutphin PD, Reis SP, McKune A, Ravanzo M, Kalva SP, Pillai AK. Improving inferior vena cava filter retrieval rates with the define, measure, analyze, improve, control methodology. J Vasc Interv Radiol. 2015;26:491-498.e 1.

36. Zhan C, Miller MR. Administrative data based patient safety research: a critical review. Qual Saf Health Care. 2003;12(suppl 2):ii58-ii63.

37. Schneeweiss S, Avorn J. A review of uses of health care utilization databases for epidemiologic research on therapeutics. J Clin Epidemiol. 2005;58:323337.

38. Aziz F, Spate K, Wong J, Aruny J, Sumpio B. Changing patterns in the use of inferior vena cava filters: review of a single center experience. J Am Coll Surg. 2007;205:564-569.

39. Uberoi R, Tapping CR, Chalmers N, Allgar V. British Society of Interventional Radiology (BSIR) Inferior Vena Cava (IVC) Filter Registry. Cardiovasc Intervent Radiol. 2013;36:1548-1561.

40. Tao MJ, Montbriand JM, Eisenberg N, Sniderman KW, Roche-Nagle G. Temporary inferior vena cava filter indications, retrieval rates, and follow-up management at a multicenter tertiary care institution. J Vasc Surg. 2016;64:430-437.

41. Wang SL, Cha HH, Lin JR, Francis B, Elizabeth W, Martin P, Rajan S. Impact of physician education and a dedicated inferior vena cava filter tracking system on inferior vena cava filter use and retrieval rates across a large US health care region. J Vasc Interv Radiol. 2016;27:740-748. 


\section{Journal of the American Heart Association \\ OPEN ACCESS f}

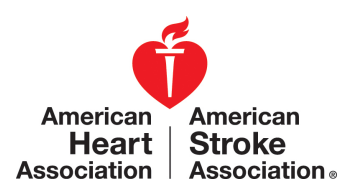

Vena Cava Filter Retrieval Rates and Factors Associated With Retrieval in a Large US Cohort
Joshua D. Brown, Driss Raissi, Qiong Han, Val R. Adams and Jeffery C. Talbert

J Am Heart Assoc. 2017;6:e006708; originally published September 4, 2017; doi: 10.1161/JAHA.117.006708

The Journal of the American Heart Association is published by the American Heart Association, 7272 Greenville Avenue, Dallas, TX 75231

Online ISSN: 2047-9980

The online version of this article, along with updated information and services, is located on the World Wide Web at:

http://jaha.ahajournals.org/content/6/9/e006708

Subscriptions, Permissions, and Reprints: The Journal of the American Heart Association is an online only Open Access publication. Visit the Journal at http://jaha.ahajournals.org for more information. 